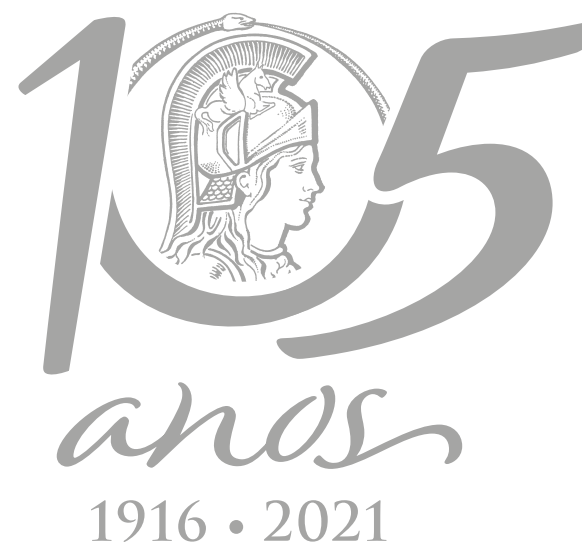

\title{
Antidiabetic properties of oral treatment of hexane and chloroform fractions of Morus nigra leaves in streptozotocin-induced rats
}

\author{
DIONÍSIO H.A. DA SILVA, HUMBERTO M. BARBOSA, JULY F. DA SILVA, CELUANE A. \\ MOURA, DAYANE A. GOMES, JACKSON R.G.S. ALMEIDA \& EDUARDO C. LIRA
}

\begin{abstract}
Morus nigra L. has been widely used in Brazilian folk medicine for the treatment of diabetes. We evaluate the chemical composition and antidiabetic properties of the hexane (Hex-Mn) and chloroform (Chlo-Mn) fractions obtained by partition of the crude ethanolic extract from the leaves in rats. Chemical composition analysis of Hex-Mn and Chlor-Mn was performed by gas chromatography-mass spectrometry (CG-MS). In vivo and in vitro studies were carried out to compare the antidiabetic activities of the Hex-Mn and Chlor-Mn fractions. Most of the compounds identified in Hex-Mn were $\alpha$-linolenic acid, stigmast-5-en-3-ol and linolenic acid ethyl ester, while in Chlor-Mn, stigmast5-en-3-ol, palmitic acid and $\alpha$-linolenic acid were mainly identified. Only Hex-Mn treatment reduced both fasting and postprandial hyperglycemia. Additionally, Hex-Mn preserved body weight gain, preserved the hepatic glycogen content, and also reduced the thiobarbituric acid reactive substances and nitrite levels, as well as restored the superoxide dismutase. Furthermore, digestion of complex carbohydrates and intestinal glucose absorption was prevented by Hex-Mn treatment. Our results suggest that the antidiabetic activity of Hex-Mn may be explained, at least in part, by the insulin sensitivity increase, antioxidant properties and reduction in carbohydrate absorption in the small intestine.
\end{abstract}

Key words: Diabetes mellitus, Morus nigra, antidiabetic effect, antioxidant effect, nutraceutical.

\section{INTRODUCTION}

Diabetes mellitus (DM) conditions are recognized for persistent hyperglycemia, which is due to compromised insulin synthesis by beta cells of the pancreatic islet and/or loss of insulin action in the target tissue (Júnior et al. 2017, Barbosa et al. 2018). Nowadays, DM has become a worldwide medical emergency in developed and developing countries. It is reported that about 425 million adults are living with DM, whom 1 of out of 2 is undiagnosed (IDF 2019). Despite the pharmacology therapy efficacy in glycemic control, its use has been limited by side effects of medicines. In light of that, the use of plants as functional food or alternative medicines has been widely accepted to prevent and treat DM (Thaipitakwong et al. 2018).

It is noteworthy that postprandial glucose control deteriorates before fasting blood glucose (FBG) (Rizza 2010). There is also evidence showing that postprandial hyperglycemia (PPH) may be an independent risk factor for the development of diabetes comorbidities, such as micro and macrovascular diseases (Rizza 2010, Gerich 2013). In addition, a growing body of evidence indicates that PPH induces severe oxidative stress, which is caused by the generation of 
free radicals such as oxygen and nitric species (ROS/NOS) associated to reduce the antioxidant enzymes such as superoxide dismutase (SOD), glutathione peroxidase (GPX) and catalase (CAT), and non-enzymatic antioxidant defense (Giri et al. 2018, Konda et al. 2019). Oxidative stress in DM may impair insulin signaling and promote glycation of protein, glucose oxidation and lipid peroxidation, which are involved with the progressive degeneration in the diabetes status (Giri et al. 2018, Ogar et al. 2019).

For this, it is critical to monitor and treat PPH as a tool to prevent or retard the manifestation of diabetes-related complications. Synthetic a-glucosidase inhibitors, such as acarbose, have beneficial effects against PPH in diabetic individuals by inhibiting $\alpha$-glucosidase, which hydrolyzes carbohydrate and releases monosaccharides for absorption in the small intestine (Yusoff et al. 2015). However, according to individual variation and abdominal discomfort, their clinical use has been limited (Fujisawa et al. 2005).

Medicinal plants are particularly interesting because not only can they be used as alternative medicines to prevent metabolic diseases, but also serve as an interesting source of potential drug candidate molecules, including inhibitors of the carbohydrate digestion, insulin sensitizers and antioxidant potential (Yusoff et al. 2015, Bin-Juman, 2019). Among them, species from the genus Morus (Moraceae) are widely distributed in Asia, Africa, Europe and America. They have been established as a functional food because of their phytochemicals and nutrients profile (Rodrigues et al. 2019). Morus nigra L. (black mulberry) is a native plant from Asia, but it is widely cultivated in Brazil, particularly in the Caatinga biome (Júnior et al. 2017). It is popularly used to treat several diseases, especially diabetes and its comorbidities in Northeast of Brazil (Araújo et al. 2015, Júnior et al. 2017).
The antidiabetic effect of the crude and aqueous extracts of $M$. nigra leaves has been demonstrated (Volpato et al. 2011, Araújo et al. 2015, Júnior et al. 2017). Therefore, the goal of this work was to evaluate the in vivo effect of hexane and chloroform fractions obtained by partition of the crude ethanolic extract of Morus nigra leaves in hyperglycemia, lipid profile, carbohydrate digestion and absorptive ratio, and oxidative stress in streptozotocin-induced diabetics in rats.

\section{Abbreviations}

ALB, albumin; Al, atherogenic index; ATL, alanine aminotransferase; ANOVA, analysis of variance; AST, aspartate aminotransferase; BBM, brush border membrane; BUN, blood urea nitrogen; CAT, catalase; Chlro-Mn, chloroform fraction; CRE, plasmatic creatinine; DM, diabetes mellitus; EDL - extensor digitorium longus; EPI - epididymal adipose tissue; FBG, fasting blood glucose; GC-MS, gas chromatographymass spectrometry; GLUT, glucose transporter; GPx, glutathione peroxidase; GSH, glutathione, GSSG, oxidized glutathione; HDL-C, high-density lipoprotein cholesterol; HGP, hepatic glucose production; Hex-Mn, hexane fraction; ITT, insulin tolerance test; MDA, malondialdehyde; NO, nitric oxide; OGTT, oral glucose tolerance test; OSTT, oral starch tolerance test; OSUTT oral sucrose tolerance test; PPH, postprandial hyperglycemia; RETRO, retroperitoneal adipose tissue; RNS, reactive nitrogen species; ROS, reactive oxygen species; S.E.M., standard error of the mean; SGLT, sodium glucose cotransporter; SOD, superoxide dismutase; STZ, streptozotocin; TBAR, thiobarbituric acid; Ti, tibia.; TC, total cholesterol; TG, triglycerides; VLDL-C, very low density lipoprotein. 


\section{MATERIALS AND METHODS}

\section{Plant material and preparation of the extract}

Morus nigra L. leaves were collected in Casa Nova (Coordinates 9²7'74.35" S; 4085'03.23" W), State of Bahia, Brazil, in October 2016. A voucher specimen (\#1764) was deposited at the Vale do São Francisco Herbarium (HVASF) at the Federal University of Vale do São Francisco (UNIVASF). The extract was prepared by maceration of dried and powdered leaves (714 g) with 95\% ethanol during three days, at room temperature. The extractive solution was concentrated under vacuum in a rotary evaporator at $50{ }^{\circ} \mathrm{C}$. The crude ethanolic extract was suspended in a mixture of methanol and water $\left(\mathrm{MeOH}: \mathrm{H}_{2} \mathrm{O}\right.$, $3: 7, v / v)$ and partitioned with $n$-hexane and chloroform (250 ml, 3x) to obtain hexane (Hex$\mathrm{Mn}$ ) and chloroform (Chlor-Mn) fractions, which were tested for its biological activity. The access to genetic patrimony and associated traditional knowledge was carried out and the project was registered in SisGen (Register \#AC34CFC).

\section{Chemicals}

Homologous series of $n$-alkanes $\left(\mathrm{C}_{10} \mathrm{H}_{22}-\mathrm{C}_{40} \mathrm{H}_{82}\right)$ were purchased from Merck (Germany). All solvents (ethanol, hexane and chloroform) were purchased from Synth ${ }^{\oplus}$ (Brazil).

\section{Gas chromatography-mass spectrometry (GC- MS) analysis}

The analysis of chemical constituents present in Hex-Mn and Chlor-Mn was performed by GC-MS using a Shimadzu ${ }^{\circledR}$ gas chromatograph (QP-2010 ULTRA) interfaced with a mass spectrometer, employing the following chromatographic conditions: Phenomenex ${ }^{\circledR}$ ZB-5MS Zebron column (30.0 m x $0.25 \mathrm{~mm} \times 0.25 \mu \mathrm{m})$; helium (99.999\%) carrier gas at a constant flow of 1.40 $\mathrm{ml} / \mathrm{min} ; 1 \mu \mathrm{l}$ injection volume; injector split ratio of 1:40; injector temperature $260^{\circ} \mathrm{C}$; electron ionization at $70 \mathrm{eV}$; ion source temperature 250 ${ }^{\circ} \mathrm{C}$. The oven temperature was programmed from $60{ }^{\circ} \mathrm{C}$ to $320^{\circ} \mathrm{C}$ in $25 \mathrm{~min}$. A mixture of linear hydrocarbons $\left(\mathrm{C}_{10} \mathrm{H}_{22}-\mathrm{C}_{40} \mathrm{H}_{82}\right)$ was injected under the same experimental conditions.

\section{Identification of compounds}

The data were acquired and processed with a PC with Shimadzu GC-MS-Solution software. The identification of the constituents was assigned on basis of comparison of their relative retention indices to a $n$-alkane homologous series obtained by co-injecting the samples, as well as, by comparison of their mass spectra with those of authentic compounds or with reference spectra in the computer library (Wiley7lib and NIST08lib) and other published mass spectra. A similarity index of at least 90 was considered for the identification of compounds.

\section{Animals}

Adult male Wistar rats (190-210 g) were housed in individual cages, under controlled conditions, such as 12/12 h light/dark cycle (lights on at 6:00 a.m.) at room temperature $\left(22 \pm 2^{\circ} \mathrm{C}\right)$. All rats were fed with a standard lab chow (Presence, Purina ${ }^{\oplus}$ ) and water ad libitum. The protocols were approved by the Animal Ethics Committee of the Federal University of Pernambuco (CEUAUFPE, process \#23076.016693/2014-88) and conducted All experiments were cared for in compliance with the Guide for the Care and Use of Laboratory Animals of the Brazilian National Council for Animal Experimentation.

\section{Experimental diabetes mellitus (DM)}

Streptozotocin (STZ, 40 mg/kg, Sigma ${ }^{\circledR}$, St. Louis, MO, USA) dissolved in citrate buffer ( $\mathrm{pH} 4.5$ ) was injected into the jugular vein of rats that previously fasted for $12 \mathrm{~h}$. Five days after STZ injection, animals with postprandial glycaemia above $250 \mathrm{mg} / \mathrm{dL}$ and clear signs of DM (polyuria, 
polydipsia and polyphagia) were considered as diabetic, and thus included in the experimental protocol (Barbosa et al. 2018). The glycaemia was measured by One Touch Ultra (Johnson \& Johnson ${ }^{\oplus}$ ). In order to perform the control group, non-diabetic animals received citrate buffer injection as control. Five days after STZ injection, animals were randomly divided into five different groups ( $n=5-7$ per group): non-diabetic control (C); diabetic (D); diabetic treated with $400 \mathrm{mg} / \mathrm{kg}$ of hexane (DHex-Mn) and $400 \mathrm{mg} /$ $\mathrm{kg}$ of chloroform (DChlo-Mn) fractions; diabetic treated with insulin (DI). The diabetic and nondiabetic groups (except DI) received the extract samples or water (i.e., control groups) orally by orogastric tube (gavage) once daily for 21 days. DI received $3 \mathrm{U} /$ rat of Insulin NPH - Lilly (s.c.), at 8:00 a.m. and at 6:00 p.m., from day 0 to day 21. Afterwards, the animals were housed in a metabolic cage to measure body weight, urinary volume, as well as food and water intake daily (Barbosa et al. 2018).

\section{Biochemical analysis}

On the $21^{\text {st }}$ day of the experiment, the rats were anesthetized using ketamine (150 mg/ kg b.w) and xilazin (10mg/kg b.w) and then euthanized for the collection of blood samples and biochemical analysis, such as plasma glucose, total cholesterol (TC), high-density lipoprotein cholesterol (HDL-C), triglycerides (TG), albumin $(A L B)$, alanine (ALT), aspartate amino transferase (AST), alkaline phosphatase (ALP) and total protein (TP), as well as creatinine (CRE), blood urea nitrogen (BUN) and urinary urea. All these biochemical parameters were measured by commercially available kits (Labtest", Lagoa Santa, MG). The glycerol levels were measured by commercially available kit with minor modifications (Laborclin ${ }^{\circledR}$, Curitiba, PR).

The globulin levels (total protein - albumin) were calculated. The serum levels of extremely low-density lipoprotein cholesterol (VLDL-C) were calculated using the Friedwald formula $(\mathrm{VLDL}=\mathrm{TG} / 5)$. Atherogenic index (Al) was also calculated using the formula TC/HDL-c $(\mathrm{mg} / \mathrm{dl})$ (Zhou et al. 2018).

Urinary glucose was determined by the ortotoluidine method (Dubowski, 1962). The glycogen levels in the liver samples were measured as previously described by (Carrol et al. 1956).

\section{Body and organ weight}

Selected organs including heart, liver, kidney, skeletal muscle (soleus and extensor digitorium longus - EDL) and retroperitoneal (RETRO) and epididymal (EPI) adipose tissues were carefully excised and weighed. The right tibia bone was collected and measured for length and used to normalize the organ weight (Barbosa et al. 2018).

\section{Insulin tolerance test (IkTT)}

The insulin tolerance test (ITT) was performed on the $21^{\text {st }}$ day of treatment. Insulin $(0.75 \mathrm{U} / \mathrm{kg}$ body weight) was injected intraperitoneally in rats that previously fasted during 6 hours. Glucose values were measured in venous blood before insulin injection (baseline measurement, 0), as well as at 4, 8, 12 and 16 minutes after insulin administration. In order to measure insulin action, the constant rate of glucose clearance $\left(\mathrm{K}_{\mathrm{itt}}\right)$ was calculated during the $0-16 \mathrm{~min}$ period by standard preclinical method $\left(0.693 / \mathrm{t}_{1 / 2}\right)$, as previously described (Barbosa et al. 2018).

\section{Determination of the hepatic antioxidant state}

After 21 days of treatment, animals were euthanized and the liver was immediately excised and washed in ice-cold Tris-HCl buffer (0.1 M, pH 7.4). The liver was rinsed again in icecold $0.15 \mathrm{M}$ potassium chloride and homogenized (10\% w/v) using $0.05 \%$ potassium dihydrogen phosphate buffer ( $\mathrm{pH} 7.5$ homogenized in 10 volumes of $100 \mathrm{mM} \mathrm{KH}_{2} \mathrm{PO}_{4}$ buffer containing 
$1 \mathrm{mM}$ EDTA ( $\mathrm{pH}$ 7.4), with the addition of 1 $\mathrm{mM}$ sodium orthovanadate and $200 \mu \mathrm{g} / \mathrm{ml}$ of phenylmethanesulfonyl fluoride (PMSF), using a digital homogenizer Tissue lyzer (Quiagen ${ }^{\circledR}$ ) for no longer than 1 minute. Afterwards, the homogenates were centrifuged at 4,000 rpm for $10 \mathrm{~min}$ at $4^{\circ} \mathrm{C}$. The supernatant was collected and used for enzymatic assays. Tissue protein content was estimated by the Bradford method and the absorbance was read at a wavelength of $595 \mathrm{~nm}$, at room temperature (Bradford 1976). A total of $0.3 \mathrm{mg} / \mathrm{ml}$ of live homogenate was used to measure malondialdehyde (MDA) levels following reaction with thiobarbituric acid reaction (TBAR, $\mu \mathrm{M} / \mathrm{mg}$ protein) at 100 oC according to the method of Draper et al. (1993). The hepatic nitric oxide levels were estimated by measuring total nitrate/nitrite concentrations ( $\mu \mathrm{mol} / \mathrm{ml}$, stable end-products of NO) by the Griess method (Miranda et al. 2001). Reduced glutathione (GSH, $\mu \mathrm{mol} / \mathrm{ml}$ ) and oxidized glutathione (GSSG, $\mu \mathrm{mol} / \mathrm{ml}$ ) contents were determined as previously described by Hissin \& Hilf (1976). The redox state was estimated by the GSH/GSSG ratio. The activity of superoxide dismutase (SOD) was evaluated according to the method previously described by Misra \& Fridovich (1972) following the kinetics of the inhibition of adrenaline auto-oxidation at 480 $\mathrm{nm}$ expressed as $\mathrm{U} / \mathrm{mg}$ protein. The catalase (CAT) activity was assayed by the method of Beers \& Sizer (1952). The kinetic analysis of CAT was measured spectrophotometrically at 240 $\mathrm{nm}$ after the addition of $\mathrm{H}_{2} \mathrm{O}_{2}$. The results were expressed as $\mathrm{U} / \mathrm{mg}$ protein.

\section{Oral carbohydrate tolerance test (OGTT)}

On the $21^{\text {st }}$ day of the experiment, the oral glucose tolerance test (OGTT) was performed to assess the glucose tolerance in overnight fasted non-diabetic and diabetic rats divided into 4 groups with 5 rats each: Control group (C) was given distilled water (1 ml/ kg); diabetic (D); diabetic treated with a single dose of $400 \mathrm{mg} / \mathrm{kg}$ of Hex-Mn (Hex-Mn); and diabetic treated with a single dose of phloridzin (100 mg/ kg of b.w., v.o., Sigma ${ }^{\oplus}$ ), an inhibitor of SGLT. All animals received $2.5 \mathrm{~g}$ of glucose $/ \mathrm{kg}$ of b.w. (v.o.). Blood glucose was measured in blood samples that were collected from each rat tail. The glycemia was analyzed before ( $\mathrm{t}=0$, baseline) and then after 15, 30, 60, 90 and 120 min (Yusoff et al. 2015).

Oral sucrose tolerance test (OSucTT) and oral starch tolerance test (OSTT) were applied to a similar set of animals. Animals received sucrose or starch respectively, at $4 \mathrm{~g} / \mathrm{kg}$ of b.w., as well as acarbose (10 mg/kg of b.w., v.o. Sigma ${ }^{\circledR}$ ). The glycaemia was analyzed in both tests before $(t=0$, baseline) and then 30,60, 90 and 120 min after the animals received carbohydrate administration (Yusoff et al. 2015).

\section{Intestinal glucose absorption by the everted sac technique}

The effect of Hex-Mn on glucose absorption via isolated ratjejunal sacs was studied as previously described by Yusoff et al. (2015). Following an overnight fast, rats were euthanized under anesthesia and the abdominal wall was opened. Small segments (each about $5 \mathrm{~cm}$ ) close to the duodenum were rinsed with Krebs solution by pushing the solution softly from the syringe. The segments isolated were placed in a wellaerated solution $\left(95 \% \mathrm{O}_{2}\right.$ and $5 \% \mathrm{CO}_{2}$ ) containing $5.5 \mathrm{mM}$ glucose. The jejunum was everted and cut into 5-cm segments. Each sac was filled with $1 \mathrm{ml}$ of Krebs solution, then formed into a sac by tying both of its ends with cotton threads. Each sac was further incubated for $60 \mathrm{~min}$ at $37{ }^{\circ} \mathrm{C}$ in a test tube containing a total of $15 \mathrm{ml}$ of Krebs solution. Added to the tubes, the test substances consisted of Hex-Mn $(1 \mathrm{mg} / \mathrm{ml})$ in the intestines of control animals and diabetic animals. The tubes containing only Krebs buffer 
served as a negative control. The initial and final glucose concentrations following the incubation period were measured and the intestine glucose absorption could be calculated as follows:

Amount of glucose absorbed ( $\mathrm{mg} / \mathrm{g}$ tissue weight $)=\left(G_{\text {before }}-G_{\text {after }}\right) / W_{\text {intestine }}$

Where $G_{\text {before }}$ and $G_{\text {after }}$ represented glucose concentrations $(\mathrm{mg} / \mathrm{dl})$ before and after incubation, respectively, and $W_{\text {intestine }}$ represented the weight of the intestinal segment in grams.

\section{Statistical analysis}

GraphPad Prism $6.01^{\circ}$ was used to analyze the data. Results were expressed as mean \pm SEM . Kolmogorov-Smirnov was used as a normality test. The one-way analysis of variance, followed by Tukey's test, was employed to analyze the data between groups. The two-way analysis of variance, followed by Tukey's test, was employed to analyze intestinal absorption data. When $p<0.05$, the difference between groups was considered as statistically significant.

\section{RESULTS}

\section{Phytochemical profile}

The GC-MS chromatogram of Hex-Mn revealed the presence of 71 peaks, of which 15 were identified, corresponding to $77.81 \%$ of its total chemical composition. $\alpha$-linolenic acid (16.04\%), stigmast-5-en-3-ol (10.45\%) and linolenic acid ethyl ester (9.31\%) were the majority of compounds. The GC-MS chromatogram of ChlorMn revealed the presence of 77 peaks, of which 13 were identified, corresponding to $53.98 \%$ of its total chemical composition. Stigmast-5-en-3ol (7.28\%), palmitic acid (6.18\%) and $\alpha$-linolenic acid (5.33\%) were the majority of compounds.

\section{Antihyperglycemic and antidiabetic effect}

This study evaluated the antidiabetic properties of both hexane (Hex-Mn) and chloroform (Chlo$\mathrm{Mn}$ ) fractions in STZ-induced diabetic rats. STZ induced a sustained high fasting (576.2 \pm 59.6 vs $87.6 \pm 3.7 \mathrm{mg} / \mathrm{dl}$ of control) and postprandial $(551.9 \pm 43.1$ vs $110.0 \pm 3.2 \mathrm{mg} / \mathrm{dl}$ of control, Table I) glycemia, accompanied with the classical diabetic symptoms such as polydipsia,

Table I. Fasting and postprandial glucose at 21 day of treatment and accumulative effects of Hex-Mn and Chlor$\mathrm{Mn}$ fractions on body weight gain, food and fluid intake, urinary volume, glucose, and urea urinary in control and diabetic treated for 21 days.

\begin{tabular}{|c|c|c|c|c|c|}
\hline & \multicolumn{5}{|c|}{ Groups } \\
\hline Parameters & C & D & Hex-Mn & Chlor-Mn & DI \\
\hline $\begin{array}{c}\text { Fasting glycemia } \\
(\mathrm{mg} / \mathrm{dl})\end{array}$ & $87.6 \pm 3.7 \mathrm{a}$ & $576.2 \pm 59.6 \mathrm{~b}$ & $388.4 \pm 62.9 \mathrm{c}$ & $487.1 \pm 53.6 \mathrm{~b}$ & $352.8 \pm 37.0 \mathrm{c}$ \\
\hline $\begin{array}{c}\text { Postprandial glycemia } \\
(\mathrm{mg} / \mathrm{dl})\end{array}$ & $110.0 \pm 3.2 \mathrm{a}$ & $551.9 \pm 43.1 \mathrm{~b}$ & $329.8 \pm 30.2 \mathrm{c}$ & $613.9 \pm 70.8 \mathrm{~b}$ & $381.9 \pm 47.2 \mathrm{c}$ \\
\hline $\begin{array}{c}\text { Final body weight }(\mathrm{g}) \\
\text { Food intake }(\mathrm{g})\end{array}$ & $311.7 \pm 7.9 \mathrm{a}$ & $221.2 \pm 4.4 \mathrm{~b}$ & $262.9 \pm 3.2 \mathrm{c}$ & $246.0 \pm 10.3 \mathrm{~b}$ & $306.3 \pm 10.3 \mathrm{a}$ \\
\hline Fluid intake $(\mathrm{mL})$ & $524.3 \pm 25.9 \mathrm{a}$ & $859.2 \pm 22.6 \mathrm{~b}$ & $744.4 \pm 22,8 \mathrm{c}$ & $799.3 \pm 41.2 \mathrm{~b}$ & $672.1 \pm 20.3 \mathrm{~d}$ \\
\hline Urinary volume $(\mathrm{mL})$ & $315.8 \pm 19.1 \mathrm{a}$ & $3060.1 \pm 214.2 \mathrm{~b}$ & $2247.7 \pm 179.3 \mathrm{c}$ & $2478.7 \pm 282.6 \mathrm{~d}$ & $709.1 \pm 50.5 \mathrm{~d}$ \\
\hline Urinary urea $(\mathrm{mg} / \mathrm{dL})$ & $627.1 \pm 51.9 \mathrm{a}$ & $13521.4 \pm 1431.2 \mathrm{~b}$ & $9260.5 \pm 1194.2 \mathrm{c}$ & $9802.7 \pm 643.9 \mathrm{~d}$ & $1435.0 \pm 499.7 \mathrm{~d}$ \\
\hline Urinary glucose $(\mathrm{mg} / \mathrm{mL})$ & - & $12.763 \pm 1.4 \mathrm{~b}$ & $9.802 \pm 643 \mathrm{c}$ & $12.821 .4 \pm 2.42 \mathrm{~b}$ & $1.792 \pm 553 \mathrm{~d}$ \\
\hline
\end{tabular}

Results are expressed as mean \pm SEM of 7 animals per group. Mean values with different superscript letters are statistically different at $p<0.05$ and were analyzed using one-way ANOVA followed by post-hoc Tukey's test. 
polyphagia and polyuria, as well as body weight reduction (Figure 1).

Here, only the Hex-Mn treatment reduced both FBG and PPH ( 40\%) in diabetic rats (Table I) and also the urinary glucose excretion in diabetic treated rats (Table II). Also, HexMn preserved body weight gain and inhibited hyperphagia (Figure 1), which was accompanied by reduced skeletal muscle and adipose tissue loss (Table II). Besides, this fraction also reduced urinary urea $(\sim 40 \%)$ in STZ-rats. Chlo-Mn preserved only adipose tissue and red skeletal muscle mass and also attenuated urinary urea $(\sim 30 \%)$ in STZ-rat (Tables I and II). Both fractions studied attenuated the increased fluid intake and urinary volume in diabetic rats (Table I). It is noteworthy that Hex-Mn fraction had a similar effect on hyperglycemia-lowering effects compared to insulin treatment.
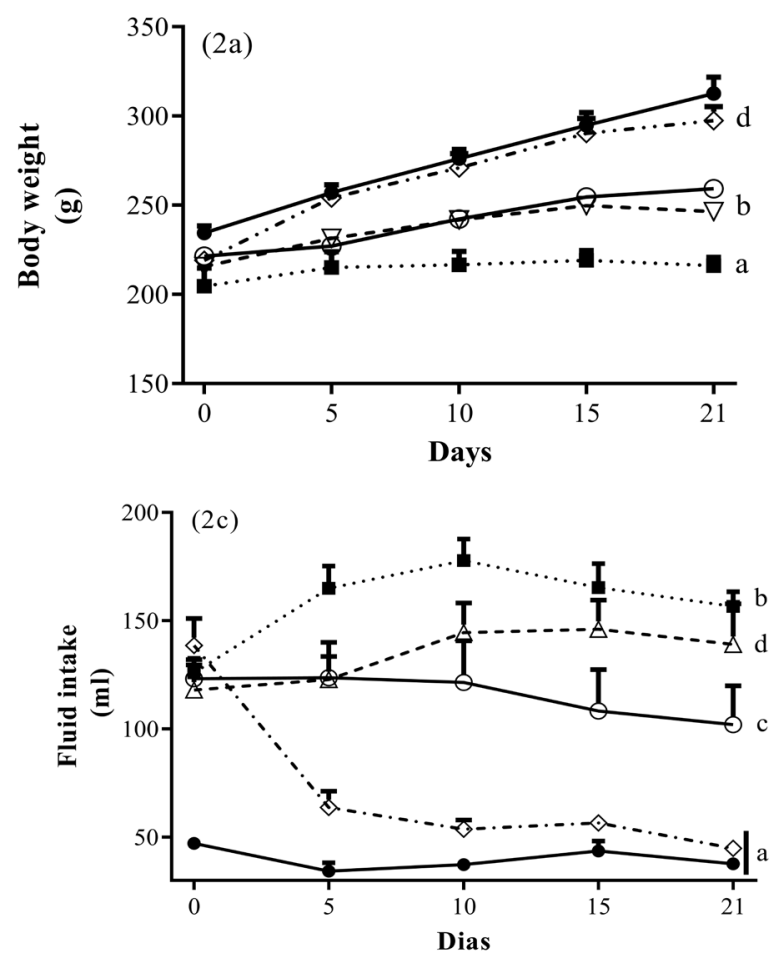

\section{Biochemical analysis}

As shown in Table III, STZ induced an increase in TC, TG and VLDL-C, without alteration in HDL-C. The damage to the lipid profile contributes to the worst atherogenic index (AI) in diabetic rats. Also, the concentrations of biomarkers of hepatic (ALT, AST and ALP) and kidney (CRE and BUN) dysfunctions were increased in diabetic rats relative to controls. The Hex-Mn treatment exhibited a lipid-lowering action, reducing TC (20\%), TG (30\%), VLDL-C (30\%) and atherogenic index (40\%), also increasing the HDL-C levels $(\sim 30 \%)$. As seen in Table III, this fraction also reduced ALT (50\%), AST (35\%), ALP (40\%) and BUN (60\%). Chlo-Mn fraction also ameliorated the TG (60\%), VLDL (40\%), BUN (35\%), ALT (55\%), AST ( 20\%) and ALP (40\%). As expected, insulin treatment was efficient to attenuate lipid and hepatic imbalance. Neither DM nor any treatment caused differences in ALB, TP and globulin levels.
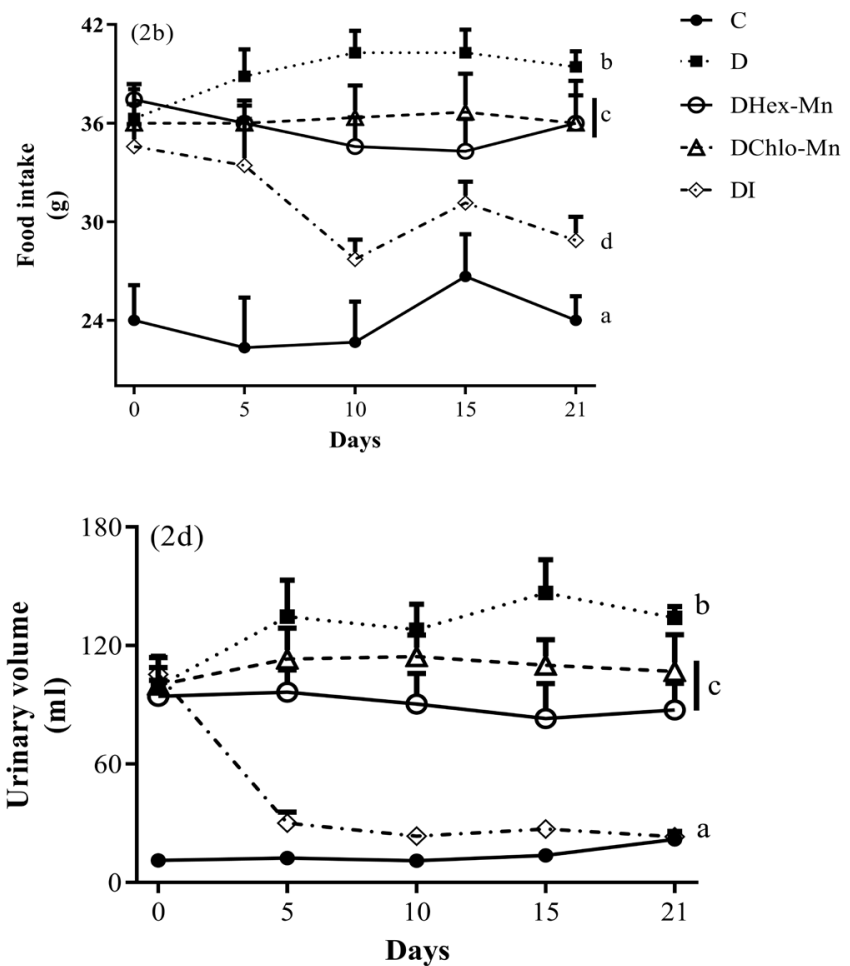

Figure 1. Effect of Hex-Mn and Chlor-Mn fractions on body weight (2a), food (2b) and fluid (2c) intake, urinary volume (2d) in control and STZ diabetic rats for 21-days treatment. Results are expressed as mean \pm S.E.M. of 7 animals per group. 
Table II. Effects of Hex-Mn and Chlor-Mn fractions on heart, liver, kidney, soleus, EDL, EPI and RETRO organ mass in control and diabetic treated for 21 days.

\begin{tabular}{|c|c|c|c|c|c|}
\hline & \multicolumn{5}{|c|}{ Groups } \\
\hline Parameters & C & D & Hex-Mn & Chlor-Mn & DI \\
\hline Heart $(\mathrm{g} / \mathrm{mm} \mathrm{Ti})$ & $25.41 \pm 1.27 \mathrm{a}$ & $20.53 \pm 0.79 \mathrm{~b}$ & $22.30 \pm 0.91 \mathrm{a}$ & $20.76 \pm 0.66 \mathrm{a}$ & $25.67 \pm 1.47 \mathrm{a}$ \\
\hline Liver $(\mathrm{g} / \mathrm{mm} \mathrm{Ti})$ & $276.9 \pm 16.9 \mathrm{a}$ & $252.6 \pm 6.7 \mathrm{a}$ & $284.5 \pm 12.5 \mathrm{a}$ & $266.2 \pm 7.6 \mathrm{a}$ & $294.7 \pm 9.3 \mathrm{a}$ \\
\hline Kidney $(\mathrm{g} / \mathrm{mm} \mathrm{Ti})$ & $65.08 \pm 2.88 \mathrm{a}$ & $65.28 \pm 2.79 \mathrm{a}$ & $66.67 \pm 2.97 \mathrm{a}$ & $62.10 \pm 1.55 \mathrm{a}$ & $60.48 \pm 2.19 \mathrm{a}$ \\
\hline Soleus $(\mathrm{g} / \mathrm{mm} \mathrm{Ti})$ & $0.758 \pm 0.059 \mathrm{a}$ & $0.536 \pm 0.019 \mathrm{~b}$ & $0.656 \pm 0.039 \mathrm{c}$ & $0.690 \pm 0.023 \mathrm{c}$ & $0.685 \pm 0.016 \mathrm{c}$ \\
\hline EDL $(\mathrm{g} / \mathrm{mm} \mathrm{Ti})$ & $0.980 \pm 0.038 \mathrm{a}$ & $0.630 \pm 0.040 \mathrm{~b}$ & $0.761 \pm 0.030 \mathrm{c}$ & $0.634 \pm 0.035 \mathrm{~b}$ & $0.923 \pm 0.019 \mathrm{a}$ \\
\hline EPI $(\mathrm{g} / \mathrm{mm} \mathrm{Ti})$ & $62.8 \pm 2.9 \mathrm{a}$ & $20.6 \pm 4.1 \mathrm{~b}$ & $47.7 \pm 4.6 \mathrm{c}$ & $42.9 \pm 5.5 \mathrm{c}$ & $66.4 \pm 5.6 \mathrm{a}$ \\
\hline RETRO $(\mathrm{g} / \mathrm{mm} \mathrm{Ti})$ & $66.24 \pm 8.48 \mathrm{a}$ & $4.31 \pm 1.81 \mathrm{~b}$ & $32.44 \pm 2,24 \mathrm{c}$ & $24.34 \pm 4.52 \mathrm{c}$ & $77.08 \pm 6.74 \mathrm{a}$ \\
\hline
\end{tabular}

Results are expressed as mean \pm SEM of 7 animals per group. Mean values with different superscript letters are statistically different at $p<0.05$ and were analyzed using one-way ANOVA followed by post-hoc Tukey's test.

Table III. Effect of Hex-Mn and Chlor-Mn fractions on biochemical and lipid profile in control and diabetic treated for 21 days.

\begin{tabular}{|c|c|c|c|c|c|}
\hline & \multicolumn{5}{|c|}{ Groups } \\
\hline Parameters & C & D & Hex-Mn & Chlor-Mn & DI \\
\hline TG $(\mathrm{mg} / \mathrm{dL})$ & $35.3 \pm 3.2 \mathrm{a}$ & $168.2 \pm 10.1 \mathrm{~b}$ & $116.1 \pm 5.2 \mathrm{c}$ & $71.7 \pm 15.9 \mathrm{~d}$ & $56.6 \pm 4.9 \mathrm{e}$ \\
\hline TC $(\mathrm{mg} / \mathrm{dL})$ & $44.87 \pm 3.13 \mathrm{a}$ & $64.03 \pm 4.12 \mathrm{~b}$ & $52.88 \pm 4.08 \mathrm{c}$ & $59.62 \pm 3.42$ & $61.31 \pm 2.68$ \\
\hline HDL-C $(\mathrm{mg} / \mathrm{dL})$ & $34.7 \pm 2.4 \mathrm{a}$ & $31.9 \pm 2.2 \mathrm{a}$ & $40.9 \pm 3.1 \mathrm{~b}$ & $31.4 \pm 3.0 \mathrm{a}$ & $36.9 \pm 2.9 \mathrm{~d}$ \\
\hline VLDL-C $(\mathrm{mg} / \mathrm{dL})$ & $6.45 \pm 0.15 \mathrm{a}$ & $33.6 \pm 2.0 \mathrm{~b}$ & $23.7 \pm 1.1 \mathrm{c}$ & $19.9 \pm 3.6 \mathrm{c}$ & $11.3 \pm 0.9 \mathrm{c}$ \\
\hline Atherogenic $/ \mathrm{ndex}(\mathrm{AU})$ & $1.2 \pm 0.1 \mathrm{a}$ & $1.9 \pm 0.2 \mathrm{~b}$ & $1.2 \pm 0.06 \mathrm{c}$ & $1.9 \pm 0.2 \mathrm{~b}$ & $1.5 \pm 0.1 \mathrm{c}$ \\
\hline ALT $(\mathrm{U} / \mathrm{mL})$ & $50.6 \pm 3.2 \mathrm{a}$ & $255.6 \pm 31.3 \mathrm{~b}$ & $124.0 \pm 6.7 \mathrm{c}$ & $115.4 \pm 8.9 \mathrm{c}$ & $102.0 \pm 6.3 \mathrm{c}$ \\
\hline AST $(\mathrm{U} / \mathrm{mL})$ & $139.3 \pm 25.1 \mathrm{a}$ & $254.9 \pm 22.5 \mathrm{~b}$ & $219.8 \pm 17.1 \mathrm{c}$ & $198.9 \pm 15.6 \mathrm{c}$ & $205.8 \pm 8.3 \mathrm{c}$ \\
\hline ALP $(\mathrm{mg} / \mathrm{dL})$ & $32.9 \pm 4.2 \mathrm{a}$ & $138.5 \pm 11.8 \mathrm{~b}$ & $86.7 \pm 5.0 \mathrm{c}$ & $86.3 \pm 12.1 \mathrm{c}$ & $66.3 \pm 6.6 \mathrm{c}$ \\
\hline BUN $(\mathrm{mg} / \mathrm{dL})$ & $7.33 \pm 1.3 \mathrm{a}$ & $104.6 \pm 17.2 \mathrm{~b}$ & $41.8 \pm 3.7 \mathrm{c}$ & $68.9 \pm 10.6 \mathrm{~d}$ & $10.0 \pm 0.43 \mathrm{c}$ \\
\hline CRE $(\mathrm{mg} / \mathrm{dL})$ & $0.46 \pm 0.03 \mathrm{a}$ & $0.60 \pm 0.03 \mathrm{~b}$ & $0.63 \pm 0.02 \mathrm{~b}$ & $0.64 \pm 0.05 \mathrm{~b}$ & $0.59 \pm 0.07 \mathrm{~b}$ \\
\hline Albumin $(\mathrm{mg} / \mathrm{dL})$ & $2.8 \pm 0.2 \mathrm{a}$ & $2.43 \pm 0.2 \mathrm{a}$ & $2.49 \pm 0.01 \mathrm{a}$ & $2.4 \pm 0.1 \mathrm{a}$ & $2.6 \pm 0.1 \mathrm{a}$ \\
\hline Total protein $(\mathrm{mg} / \mathrm{dL})$ & $5.8 \pm 0.3 \mathrm{a}$ & $5.9 \pm 0.2 \mathrm{a}$ & $6.8 \pm 0.2 \mathrm{a}$ & $6.2 \pm 0.3 \mathrm{a}$ & $6.1 \pm 0.4 \mathrm{a}$ \\
\hline Globulin $(\mathrm{mg} / \mathrm{dL})$ & $3.5 \pm 0.3 \mathrm{a}$ & $3.4 \pm 0.1 \mathrm{a}$ & $4.4 \pm 0.2 \mathrm{a}$ & $4.3 \pm 0.4 \mathrm{a}$ & $4.5 \pm 0.3 \mathrm{a}$ \\
\hline
\end{tabular}

Results are expressed as mean \pm SEM of 7 animals per group. Mean values with different superscript letters are statistically different at $p<0.05$ and were analyzed using one-way ANOVA followed by post-hoc Tukey's test.

\section{Glycerol, glycogen and IkTT levels}

As shown in Table IV, STZ induced both a rise in glycerol levels (3.4-fold) and a reduction in hepatic glycogen ( $85 \%)$. The Hex-Mn reduced glycerol levels ( $60 \%)$ and preserved the hepatic glycogen content as much as insulin. Chlor-Mn fraction did not cause any improvement in these parameters. The insulin treatment elevated the hepatic glycogen content (3.3-fold). In addition, the reduction in insulin tolerance (IkTT) induced by STZ was ameliorated by Hex-Mn treatment. 
Table IV. Effect of Hex-Mn and Chlor-Mn fractions on IkTT, serum glycerol and hepatic glycogen in control and diabetic treated for 21 days.

\begin{tabular}{|c|c|c|c|c|c|}
\hline & \multicolumn{5}{|c|}{ Groups } \\
\hline Parameters & C & D & Hex-Mn & Chlor-Mn & DI \\
\hline IkTT & - & $2.7 \pm 0.5 \mathrm{~b}$ & $4.4 \pm 0.4 \mathrm{c}$ & - & - \\
\hline Glycerol (mg/dL) & $23.1 \pm 3.3 \mathrm{a}$ & $79.4 \pm 7.4 \mathrm{~b}$ & $32.4 \pm 6.3 \mathrm{c}$ & $56.8 \pm 1.3 \mathrm{~d}$ & \\
\hline Hepatic glycogen (\%/g of tissue) & $5.10 \pm 0.23 \mathrm{a}$ & $0.72 \pm 0.11 \mathrm{~b}$ & $2.6 \pm 0.17 \mathrm{c}$ & $1.21 \pm 0.27 \mathrm{~d}$ & $2.48 \pm 0.21 \mathrm{c}$ \\
\hline
\end{tabular}

Results are expressed as mean \pm SEM of the mean of $5-7$ animals per group. Mean values with different superscript letters are statistically different at $p<0.05$ and were analyzed using one-way ANOVA followed by post-hoc Tukey's test.

\section{Antioxidant activities}

Considering that the antioxidant properties are one of the most important mechanisms involved in the anti-hyperglycemic effects of plant extracts, we decided to analyze the antioxidant effects only in Hex-Mn fraction, mainly because the Chlo-Mn did not improve hyperglycemia. The hepatic lipid peroxidation was determined by evaluating the concentration of thiobarbituric acid reactive substances (TBARS), which were expressed regarding malondialdehyde (MDA) content. STZ induced the pro-oxidant status in the liver, which was accompanied by both increasing in TBARS and nitrite content (60\%), and GSH:GSSG ratio (20\%) and reduction in SOD (40\%) antioxidant activity (Table V). Hex$\mathrm{Mn}$ treatment reduced the TBARS and nitrite levels, as well as restored the SOD activity back to normal in diabetic rats (Table V), but it did not improve the GSH:GSSG ratio. Catalase activity was not modified by any conditions evaluated.

\section{Oral carbohydrates tolerance tests}

Since only Hex-Mn had an antihyperglycemic effect in STZ diabetic rats, we estimate the in vivo effect of Hex-Mn fraction on postprandial hyperglycemia reduction. As seen in Figure 2 , this fraction inhibited the rise in the blood glucose levels after carbohydrate overload. The baseline of fasting glucose level was higher in diabetic non-treated animals as expected. After the overload of glucose, the peak blood glucose level was $231.75 \mathrm{mg} / \mathrm{dl}$ in the control rats. Diabetic non-treated rats $(2 \mathrm{a})$ reached the peak blood glucose level at $579.8 \mathrm{mg} / \mathrm{dl}$ and its glycemia remained higher throughout the experimental period. The control animals returned glycemia to basal levels at 120 minutes of the experiment. Hex-Mn treatment attenuated the peak of blood glucose levels (25\%). The increase in the glucose absorption induced by diabetes (3.3-fold) was reduced by Hex-Mn diabetic rats (30\% lower in the area under the curve, Figure 2b). Phloridzin, a competitive inhibitor of SGLT1, reduced the glucose absorption (50\%) in diabetic rats.

There was an increase in glucose levels after sucrose overload (Figure 2c), reaching its peak within $30 \mathrm{~min}(510 \mathrm{mg} / \mathrm{dl})$ in the diabetic group. In Hex-Mn-treated animals, the peak was delayed to 60 minutes of experiment with a lower value $(421 \mathrm{mg} / \mathrm{dl}$ ). After the starch overload (Figure 2e), the increase in glycemia was much lower than the increase observed in glucose and sucrose overload. Diabetic rats increased glycemia after the starch overload, which was not observed in the Hex-Mn-treated group (Figure 2). The reduction in the area under the curve of the OSUTT (Figure 2d, 25\%) and starch (Figure 2f, 50\%) in Hex-Mn-treated rats may represent an inhibition of digestion of the complex carbohydrates by disaccharidases. 
Table V. Effects of Hex-Mn and Chlor-Mn on SOD, catalase, nitrite, TBARS, GSH and GSSH in the liver in control and diabetic treated for 21 days.

\begin{tabular}{|c|c|c|c|}
\hline \multirow[b]{2}{*}{ Parameters } & \multicolumn{3}{|c|}{ Groups } \\
\hline & C & D & Hex-Mn \\
\hline $\begin{array}{c}\text { SOD } \\
\text { (U/mg protein) }\end{array}$ & $29.9 \pm 3.8 a$ & $18.5 \pm 0.8 b$ & $26.5 \pm 3.2 \mathrm{a}$ \\
\hline $\begin{array}{c}\text { Catalase } \\
\text { (U/mg protein) }\end{array}$ & $0.026 \pm 0.004 \mathrm{a}$ & $0.027 \pm 0.003 b$ & $0.025 \pm 0.005 b$ \\
\hline $\begin{array}{l}\text { Nitrite } \\
(\mu \mathrm{M})\end{array}$ & $2.3 \pm 0.2 \mathrm{a}$ & $3.7 \pm 0.2 b$ & $3.3 \pm 0.1 c$ \\
\hline $\begin{array}{c}\text { TBARS } \\
(\mu \mathrm{M} / \mathrm{mg} \text { protein) }\end{array}$ & $2.7 \pm 0.18 a$ & $4.3 \pm 0.5 b$ & $2.3 \pm 0.04 \mathrm{C}$ \\
\hline $\begin{array}{c}\text { GSH } \\
(\mu \mathrm{mol} / \mathrm{ml})\end{array}$ & $8.6 \pm 0.2 a$ & $9.4 \pm 0.6 \mathrm{a}$ & $7.8 \pm 0.2 \mathrm{a}$ \\
\hline $\begin{array}{c}\text { GSSG } \\
(\mu \mathrm{mol} / \mathrm{ml})\end{array}$ & $2.8 \pm 0.3 a$ & $3.8 \pm 0.2 b$ & $4.0 \pm 0.5 b$ \\
\hline Ratio GSH:GSSG & $3.1 \pm 0.4 \mathrm{a}$ & $2.5 \pm 0.3 b$ & $2.0 \pm 0.3 b$ \\
\hline
\end{tabular}

Results are expressed as mean \pm SEM of 5 animals per group. Mean values with different superscript letters are statistically different at $p<0.05$ and were analyzed using one-way ANOVA followed by post-hoc Tukey's test.
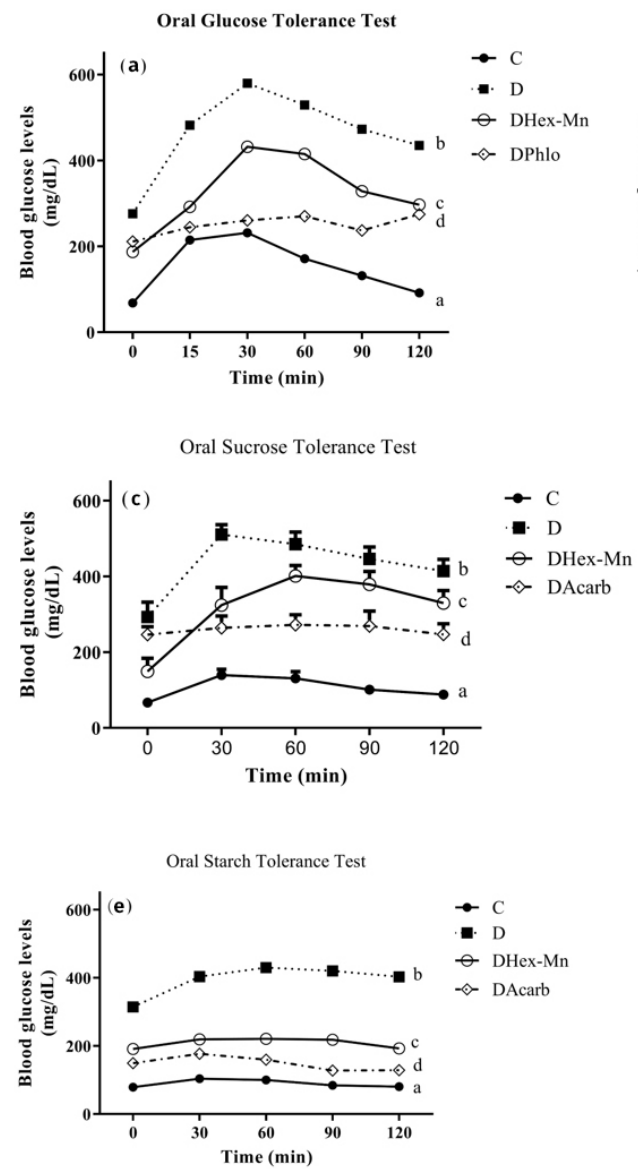
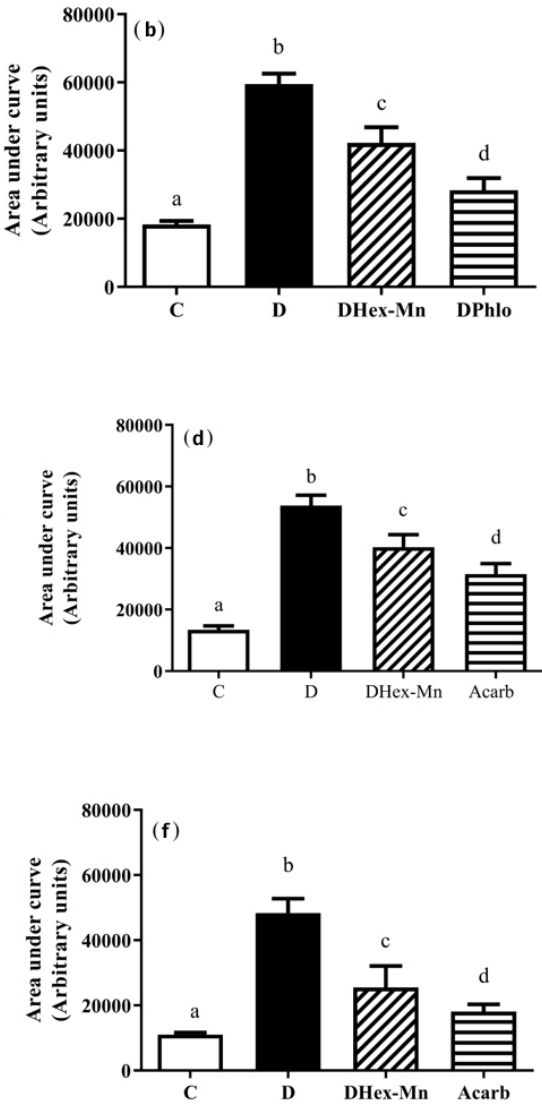

Figure 2. Effect of Hex-Mn fraction on carbohydrate oral tolerance test in control and STZ diabetic rats treated for 21 days. (a, c, e) Glycemia levels before $(t=0)$ and after glucose load in rats treated for 21 days; ( $b ; d, f)$ area under the curve (AUC) of the oral carbohydrate tolerance test. Results are expressed as mean \pm S.E.M. of 7 animals per group. Mean values with different superscript letters are statistically different at $p<0.05$ and were analyzed using one-way. 


\section{Intestinal glucose absorption}

Next, we attempted to study the role of Hex-Mn in modulating jejunal glucose absorption. As shown in Figure 3, diabetes caused the elevation in intestinal glucose absorption ( $80 \%)$, which was attenuated by Hex-Mn treatment (60\%).

\section{DISCUSSION}

Diabetes is an important public health emergency for the $21^{\text {st }}$ century, with a frightening increase in morbidity and mortality for the coming decades (IDF 2019). The role of medicinal plants in the health care system worldwide has been recognized, mainly in low- and middleincome countries (Srujana et al. 2018). The glycemic control is therefore a major challenging task because of side effects associated with synthetic drugs used in the clinic, such as biguanide (metformin), sulfonylurea, rosiglitazone and $\alpha$-glucosidase inhibitors (Jiao et al. 2017). Plants have been used to treat several diseases, especially DM. The antidiabetic effect of Morus nigra species or blackberry has been demonstrated. The ethanolic extract of M. nigra has antidiabetic, anti-hyperglycemic, antioxidant and lipid-lowering effects, with a few adverse effects (Volpato et al. 2011, Araújo

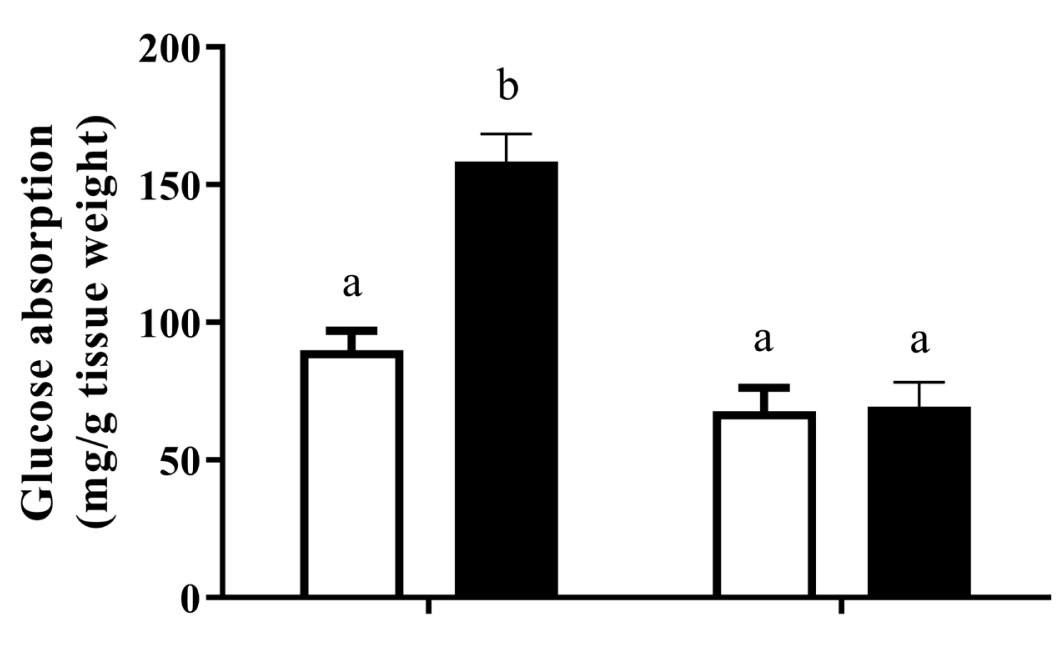

(-) Hex-Mn

(+) Hex-Mn et al. 2015, Júnior et al. 2017). Here, we show, for the first time, that the hexane and chloroform fractions from the ethanolic extract of $M$. nigra leaves may be a source of antidiabetic and antihyperglycemic molecules that may be used in the treatment of DM.

The genus Morus has a long history in Traditional Chinese Medicine and also became valued by the ethnopharmacology of several other cultures and countries. The GCMS analysis of the hexane fraction of $M$. nigra extract led to the identification of fatty acids and their esters, such as elaidolinoleinic acid, 24-ethylcholestol and ethyl linolenate. The major molecule class present in the hexane fraction is polyunsaturated fatty acids (PUFA), which prevents diabetes and their comorbidities, such as cardiovascular disease and dyslipidemia (Derosa et a. 2012). In addition, the linoleic acid (LA) and ethyl linolenate (EL) described here and also described in M. alba fruits extract, which exhibits a potent anti-inflammatory effect through the inhibition of nitric oxide production in murine macrophage stimulated by lipopolysaccharide (Qin et al. 2015). Likewise, stigmast-5-en-3-ol has shown an in vitro insulinlike effect, which stimulates glucose transport in L6 myotubes and inhibits the protein tyrosine 
phosphatase 1B (PTP1B), the major negative regulator of insulin signaling (Sujatha et al. 2010, SarathKumar \& Lakshmi 2019). Besides, it exhibits antiadipogenic activity by maintaining the glucose and lipid homeostasis (SarathKumar \& Lakshmi 2019).

The GC-MS analysis of the chloroform fraction led to the identification of loliolide acid, a member of benzofurans; stigmast-5-en3-ol and ascorbic acid, a natural antioxidant. It is well known that heterocycle molecules, such as benzofuran, have attracted attention because of the presence in natural products, biologically active compounds and potential applications as anti-inflammatory, antidepressant, antihyperglycemic and lipid-lowering agent (Nguyen et al. 2010, Shamsuzzaman 2015). The presence of ascorbic acid in the extract of Morus nigra leaves was previously demonstrated by Zeni et al. (2017), while the loliolide presence was identified in the dichloromethane-soluble fraction from M. alba (Hunyadi et al. 2013). Taken together, this is the first description of hexane and the chloroform fraction of the Morus nigra leaves, which clearly shows that this species may be used as a source of molecules for adjuvant therapy targeting the treatment of diabetes. Besides that, the chemical characterization of the species belonging to the Morus genus has shown not only medicinal, but also dietary purposes with promising nutritional support.

Previous reports from our group, as well as others, have shown clearly that the ethanolic extract of M. nigra leaves has glucose-lowering effect (Volpato et al. 2011, Júnior et al. 2017, Araújo et al. 2015). For that, we fractionated the ethanolic extract of $M$. nigra leaves in solvent polarity gradient to analyze the antidiabetic effects of the hexane and chloroform fractions. Also, for the first time, we report that Hex-Mn fraction reduced both FBG and $\mathrm{PPH}$ in STZinduced diabetic rats. Also, Hex-Mn ameliorated all canonical signs of DM such as polyuria, polydipsia, food intake and weight gain. Antihyperglycemic and antidiabetic effects of certain plants have been explained by several mechanisms such as the increase in insulin secretion in-pancreatic cells, improvement in insulin sensibility by peripheral tissues and inhibition of intestinal glucose absorption (Srujana et al. 2018, Silva et al. 2020).

It is noteworthy that the long-term treatment with Hex-Mn exhibited the anticatabolic action in the skeletal muscle and adipose tissue, indicated by urinary urea reduction, plasma glycerol and organ weight. It is well known that insulin has a classical anabolic and anticatabolic effect. So, Hex-Mn treatment had an anticatabolic effect in diabetic rats, which may be explained, at least in part, by stimulation of the anabolic pathways in similar manner to insulin (Barbosa et al. 2018, Tokarz et al. 2018).

The major endocrine regulator of hepatic glucose production (HGP) is insulin, which controls gluconeogenesis (new synthesis of glucose), glycogenesis (glucose storage as glycogen) and glycogenolysis (glucose release via the breakdown of glycogen) (Rizza 2010, Hatting et al. 2019). It is well established that insulin inhibits HPG. Insulin enhances hepatic glycogen content by stimulating glycogen synthase and suppressing glycogen phosphorylase (Srujana et al. 2018). Excessive HGP is the most important contributor to both fasting and postprandial hyperglycemia in DM (Rizza 2010). Lactate, glycerol and amino acids account for $90 \%$ of gluconeogenic substrates. Here, Hex-Mn improved glycogen content in the liver from diabetic rats, as well as reduced glycerol levels, what suggests that the reduction in hyperglycemia is due to the inhibition of HGP by stimulating glycogen synthesis and storage and/or decreased gluconeogenesis. This effect of Hex-Mn fraction was confirmed by the augment 
of the insulin sensitivity index. In addition, Chlo-Mn reduced moderately the serum levels of gluconeogenesis substrates but, in turn, did not improve hyperglycemia in diabetic rats. It is therefore suggested that this fraction may possess molecules which, at higher levels, may not contribute to the glycemic control.

Diabetes is often associated with lipid abnormalities consisting of elevated plasma concentration of triglyceride (TG), small dense low-density lipoprotein (LDL) and reduced low high-density lipoprotein (HDL) cholesterol (Chait \& Goldberg 2017). Diabetic dyslipidemia is directly associated with the development of cardiovascular disease in diabetic patients (Vergès 2015, Zhou et al. 2018). STZ-induced diabetic rats show the classical diabetic dyslipidemia, including the worsening of the atherogenic index, usually calculated by the TG/HDL ratio (Zhou et al. 2018). Curiously, Hex-Mn fraction not only attenuated diabetic dyslipidemia but also the atherogenic index, while Chlo-Mn weakly ameliorated the TG and VLDL content. As known, insulin is a key hormone in the regulation of lipid metabolism. In adipose tissue, insulin stimulates lipid synthesis and storage while inhibits the VLDL-TG production by the reduction in circulating levels of free fatty acids (FFA), which are substrates for VLDL synthesis in hepatocytes (Vergès 2015). This effect was due to the improvement of insulin sensitivity induced by Hex-Mn fraction. In addition, the presence of stigmast-5-en-3-ol, an antilipidemic agent, could explain, at least in part, the lipid-lowering effect of both fractions studied here.

In addition to the well-known metabolic function of the liver, this organ is compromised by DM on a long-term basis, which can be observed from the increase in alanine (ALT) and aspartate (AST) aminotransferase and alkaline phosphatase levels (ALP), classical biomarkers of liver functioning (Júnior et al. 2017, Barbosa et al. 2018). ALT is a cytosolic enzyme of the hepatocyte and its increased plasma content reflects damage in cell permeability commonly associated to cell death. Extracts of species from the Morus genus have demonstrated hepatoprotective effects, such as M. alba (Jiao et al. 2017), and M. nigra (Diab et al. 2020). However, it is the first scientific report which demonstrated the hepatoprotective action of hexane and chloroform fraction of $M$. nigra leaves in STZ-rats. Our data show data both Hex$\mathrm{Mn}$ and Chlo-Mn fractions are able to protect hepatocytes probably because of the stability of cell membrane and/or parenchymal cell regeneration.

The underlying mechanism of these antidiabetes effects required further exploration. We decided to analyze the possible antidiabetic mechanism of the hexane fraction, the most effective fraction evaluated here. Hyperglycemia and hyperlipidemia lead to the excess production of reactive oxygen species (ROS) and reactive nitrogen species (RNS) which, in turn, cause lipid peroxidation and cell damage (Konda et al. 2019, Ogar et al. 2019). In addition, DM suppresses the enzymatic and non-enzymatic antioxidant defense, which together contributes to intense oxidative status seen in diabetes (Araújo et al. 2015, Júnior et al. 2017). Consistent with previous studies, the diabetic liver exhibited an increase in MDA and nitrite, coupled with reduced GSH and activity of antioxidant enzymes (Althunibat et al. 2019, Sheweita et al. 2020). The antioxidant activity of M. nigra leaves has been demonstrated (Araújo et al. 2015, Turgut et al. 2016, Júnior et al. 2017); however, this is the first report of the antioxidant activity effect of Hex-Mn. The antioxidative effect may explain, at least in part, the most important antidiabetic action of the hexane fraction when compared with the chloroform one. 
Clinical studies have indicated that postprandial hyperglycemia is an important risk for micro and macrovascular diseases in several organs such as the brain, retina, heart, liver and kidney (Gerich 2013, Silva et al. 2020). Furthermore, good management of postprandial glycemic control is crucial in the treatment of DM to prevent diabetes comorbidities. The reduction of postprandial hyperglycemia induced by Hex$\mathrm{Mn}$ in STZ rats suggested a blockage of the enzymatic digestion and absorption of the carbohydrate in the gut. The intestinal mucosa hyperplasia induced by diabetes was described in STZ-rats, which was associated with the increase in total activity of disaccharidases in the entire small intestine which, in turn, results in the enhancement of the glucose absorption (Adachi et al. 2003). Postprandial hyperglycemia controls may be achieved by modulating two physiological pathways: (1) the digestion of complex carbohydrates into absorbable monosaccharides by carbohydrate-digestive enzymes (pancreatic $\alpha$-amylase, and intestinal $\alpha$-glucosidase); and (2) intestinal absorption of those monosaccharides via intestinal glucose transporters (SGLT1 and GLUT2). The first one, Silva et al. (2020) showed that Hex-Mn acutely delayed the carbohydrate digestion, but not the glucose transport through the brush border membrane of the small intestine. Here, in vitro glucose absorption, using isolated and rat jejunum everted technique, was reduced by Hex$\mathrm{Mn}$ treatment during 21 consecutive days. It is reasonable to suggest that Hex-Mn was able to modulate the activity of the glucose transports in the enterocyte membrane. Similar inhibitory effects were seen for Hex-Mn and acarbose in vivo, during the carbohydrate oral tolerance test, which may be hypothesized that Hex-Mn, at least in part, delays the intestinal carbohydrate digestion and consequently reduces glucose absorption. These results show that Hex-Mn has also an antihyperglycemic effect regardless of the insulinotropic properties.

\section{CONCLUSIONS}

Our results suggest that fractions of the ethanolic extract of $M$. nigra leaves bear positive metabolic effects in STZ-induced diabetic rats. Hex-Mn showed potent antihyperglycemic and antidiabetic effects through different mechanisms, such as more insulin-sensitive action, antioxidant property and delay of the digestion and absorption of complex carbohydrates by the small intestine. This study reaffirms the ethnomedicinal use of the Brazilian M. nigra for the treatment of DM and its most common comorbidity. In summary, the hexane fraction of the $M$. nigra leaves may represent an important source of new molecules for the treatment of DM in the future.

\section{Acknowledgments}

The authors are grateful for the financial support of Coordenação de Aperfeiçoamento de Pessoa de Nivel Superior (CAPES), Conselho Nacional de Desenvolvimento Científico e Tecnológico (CNPq), and Instituto Nacional de Ciência e Tecnologia em Etnobiologia, Bioprospecção e Conservação da Natureza (FACEPE APQ 0562-2.01/17).

\section{REFERENCES}

ADACHI T, MORI C, SAKURAI K, SHIHARA N, TSUDA K \& YASUDA K. 2003. Morphological changes and increased sucrase and isomaltase activity in small intestines of insulindeficient and type 2 diabetic rats. Endocr J 50: 271-279 https://doi.org/10.1507/endocrj.50.271.

ALTHUNIBAT OY, AL HROOB AM, ABUKHALIL MH, GERMOUSH MO, BIN-JUMAH M \& MAHMOUD AM. 2019. Fisetin ameliorates oxidative stress, inflammation and apoptosis in diabetic cardiomyopathy. Life Sci 221: 83-92. doi: 10.1016/j. lfs.2019.02.017.

ARAÚJO CM, LÚCIO D DE P, SILVA ME, SOLDI MC, DE SOUZA GH, BRANDÃO GC, SCHULZ R \& COSTA DC. 2015. Morus nigra leaf extract improves glycemic response and redox profile in 
the liver of diabetic rats. Food Func 6: 3490-3499. https:// doi.org/10.1039/c5fo00474h.

BARBOSA HM ET AL. 2018. Spondias tuberosa inner bark extract exert antidiabetic effects in streptozotocininduced diabetic rats. J Ethnopharmacol 5: 248-257. https://doi.org/10.1016/j.jep.2018.08.038.

BEERS RF \& SIZER IW. 1952. A spectrophotometric method for measuring the breakdown of hydrogen peroxide by catalase. J Biol Chem 195: 133-140.

BIN-JUMAN MN. 2019. Antidiabetic effect of Monolluma quadrangula is mediate via modulation of glucose metabolizing enzymes, antioxidant defenses, and adiponectin in type 2 diabetic rats.Oxi Med Cell Longev 2019: 6290143.

BRADFORD MM. 1976. A rapid and sensitive method for the quantitation of microgram quantities of protein utilizing the principle of protein-dye binding. Anal Biochem 72: 248-254. https://doi.org/10.1016/0003-2697(76)90527-3.

CARROL NV, LONGLEY RW \& ROE JH. 1956. The determination of glycogen in liver and muscle by use of anthrone reagente. J Biol Chem 220: 583-593.

CHAIT A \& GOLDBERG I. 2017. Treatment of Dyslipidemia in Diabetes: Recent Advances and Remaining Questions. Diab Rep 27: 112. doi: 10.1007/ s11892-017-0942-8.

DEROSA G, CICERO AFG, FOGARI E, D'ANGELO A, BONAVENTURA A, ROMANO D \& MAFFIOLI P. 2012. Effects of $n-3$ PUFAS on postprandial variation of metalloproteinases, and inflammatory and insulin resistance parameters in dyslipidemic patients: evaluation with euglycemic clamp and oral fat load. J Clin Lipidol 6(6): 553-564. doi: 10.1016/j. jacl.2012.02.010.

DIAB KA, FAHMY MA, HASSAN EM, HASSAN ZM, OMARA EA \& ABDEL-SAMIE NS. 2020. Inhibitory activity of black mulberry (Morus nigra) extract against testicular, liver and kidney toxicity induced by paracetamol in mice. Mol Biol Rep 47(3): 1733-1749. doi: 10.1007/s11033-020-05265-1.

DRAPER HH, SQUIRES EJ, MAHMOODI H, WU J, AGARWAL S \& HADLEY M. 1993. A comparative evaluation of thiobarbituric acid methods for the determination of malondialdehyde in biological materials. Free Radic Biol Med 15(4): 353-363.

DUBOWSKI KM. 1962. An o-Toluidine method for body fluid glucose determination. Clin Chem 8: 215-235.

FUJISAWA T, IKEGAMI H, INOUE K, KAWABATA Y \& OGIHARA T. 2005. Effect of two alpha-glucosidase inhibitors, voglibose and acarbose, on postprandial hyperglycemia correlates with subjective abdominal symptoms. Metabolism 54: 387-390. doi: 10.1016/j.metabol.2004.10.004.

GERICH JE. 2013. Clinical significance, pathogenesis, and management of postprandial hyperglycemia. Arch Intern Med. 163: 1306-1316. doi: 10.1001/archinte.163.11.1306.

GIRI B, DEY S, DAS T, SARKAR M, BANERJEE J \& DAS SK. 2018. Chronic hyperglycemia mediated physiological alteration and metabolic distortion leads to organ dysfunction, infection, cancer progression and other pathophysiological consequences. An update on glucose toxicity. Biomed Pharmacother 107: 306-328. doi: 10.1016/j.biopha.2018.07.157.

HATTING M, TAVARES CD, SHARABI K, RINES AK \& PUIGSERVER P. 2019. Insulin regulation of gluconeogenesis. Ann N Y Acad Sci 1411: 21-35. doi: 10.1111/nyas.13435.

HISSIN PJ \& HILF R. 1976. A fluorometric method for determination of oxidized and reduced glutathione in tissues. Anal Bioch 74: 214-226. Doi. org/10.1016/0003-2697(76)90326-2.

HUNYADI A, VERES K, DANKO B, KELE Z, WEBER E, HETENYI A, ZUPKO I \& HSIEH T-J. 2013. In vitro anti-diabetic activity and chemical characterization of an apolar fraction of Morus alba leaf water extract. Phytother Res 27: 847-851. doi: $10.1002 /$ ptr.4803.

IDF - INTERNATIONAL DIABETES FEDERATION. 2019. The global burden. Diabetes Atlas [serial on the Internet]. $7^{\text {th }}$ ed, Belgium, 2015: 1-144. Available from: http://www.idf.org/ diabetesatlas. Accessed May 03, 2019.

JIAO Y, WANG X, JIANG X, KONG F, WAN S \& CHUNYAN Y. 2017. Antidiabetic effects of Morus alba fruit polysaccharides on high-fat diet- and streptozotocin-induced type 2 diabetes in rats. J Ethnopharmacol 199: 119-127. doi: 10.1016/j.jep.2017.02.003.

JÚNIOR IIDS ET AL. 2017. Brazilian Morus nigra attenuated hyperglycemia, dyslipidemia, and pro-oxidant status in alloxan-induced rats. Sci World J 16: 1-9. doi: $10.1155 / 2017 / 5275813$.

KONDA PY, DASARI S, KONANKI S \& NAGARAJAN P. 2019. In vivo antihyperglycemic, antihyperlipidemic, antioxidative stress and antioxidant potential activities of Syzygium paniculatum Gaerth. in streptozotocin-induced diabetic rats. Heliyon 27: 1-22. doi: 10.1016/j.heliyon.2019.e01373.

MIRANDA KM, ESPEY MG \& WINK DA. 2001. A rapid, simple spectrophotometric method for simultaneous detection of nitrate and nitrite. Nitric Oxide 5: 62-71. doi: 10.1006/ niox.2000.0319.

MISRA HP \& FRIDOVICH I. 1972. The role of superoxide anion in the autoxidation of epinephrine and a simple assay 
for superoxide dismutase. J Biol Chem 247: 3170-3175. doi: $10.1006 /$ niox.2000.0319.

NGUYEN PH, NGUYEN TNA, DAO TT, KANG HW, NDINTEH DT, MBAFOR JT \& OH WK. 2010. AMP-Activated protein kinase (AMPK) activation by benzofurans and coumestans isolated from Erythrina abyssinica. J Nat Prod 73: 598602. doi: 10.1021/np900745g.

OGAR I, EGBUNG GE, NNA VU, ATANGWHO II \& ITAM EH. 2019. Hyptis verticillata attenuates dyslipidaemia, oxidative stress and hepato-renal damage in streptozotocininduced diabetic rats. Life Sci 15: 283-293. doi: 10.1016/j. lfs.2019.01.027.

QIN J ET AL. 2015. New cytotoxic and anti-inflammatory compounds isolated from Morus alba L. Nat Prod Res 29: 1711-1718. doi: 10.1080/14786419.2014.999333.

RIZZA RA. 2010. Pathogenesis of fasting and postprandial hyperglycemia in type 2 Diabetes: Implications for Therapy. Diabetes 59(11): 2697-2707.

RODRIGUES EL, MARCELINO G, SILVA GT, FIGUEIREDO PS, GARCEZ WS, CORSINO J, GUIMARÃES RCA \& FREITAS KC. 2019. Nutraceutical and Medicinal Potential of the Morus Species in Metabolic Dysfunctions. Int J Mol Sci 20: 1-16. https://doi.org/10.3390/ijms20020301.

SARATHKUMAR B \& LAKSHMI BS. 2010. In silico investigations on the binding efficacy and allosteric mechanism of six different natural product compounds towards PTP1B inhibition through docking and molecular dynamics simulations. J Mol Model 25: 1-17. doi: 10.1007/ s00894-019-4172-7.

SHAMSUZZAMAN KH. 2015. Bioactive benzofuran derivates: a review. Eur J Med Chem 97: 483-504. doi: 10.1016/j. ejmech.2014.11.039.

SHEWEITA SA, ELHADY SA \& HAMMODA HM. 2020. Trigonella stellate reduced the deleterious effects of diabetes mellitus through alleviation of oxidative stress, antioxidant- and drug-metabolizing enzymes activities. J Ethnopharmacol 256: 1-12. doi: 10.1016/j.jep.2020.112821.

SILVA DHA, BARBOSA HM, BELTRÃO RLA, SILVA CFO, MOURA CA, CASTRO NC, ALMEIDA JRGS, GOMES DA \& LIRA EC. 2020. Hexane fraction from Brazilian Morus nigra leaves improved oral carbohydrate tolerance and inhibits $\alpha$-amylase and $\alpha$-glucosidase activities in diabetic mice. Nat Prod Res 24: 1-4.

SRUJANA M, RAMESH R \& NANJAJAH LD. 2018. Antidiabetic potential of active fraction obtained from methanolic extract of Ichnocarpusfrutescens: A possible herbal remedy. Indian J Pharmacol 50: 251-259. doi: 10.4103/ijp. IJP_24_18.
SUJATHA S, ANAND S, SANGEETHA KN, SHILPA K, LAKSHMI J, BALAKRISHNAN A \& LAKSHMI BS. 2010. Biological evaluation of (3')-Stigmast-5-en-3-ol as potent anti-diabetic agent in regulating glucose transport using in vitro model. Int J Diabetes Mellitus 2: 101-109. doi.org/10.1016/j. ijdm.2009.12.013.

THAIPITAKWONG T, NUMHOM S \& ARAMWIT P. 2018. Mulberry leaves and their potential effects against cardiometabolic risks: a review of chemical compositions, biological properties and clinical efficacy. Pharm Biol 56: 109-118. doi: 10.1080/13880209.2018.1424210.

TOKARZ VL, MACDONALD PE \& KLIP A. 2018. The cell biology of systemic insulin function. J Cell Biol 217: 2273-2289. doi: $10.1083 /$ jcb.201802095.

TURGUT NH, MERT DG, KARA H, EGILMEZ HR, ARSLANBAS E, TEPE B, GUNGOR H, YILMAZ N \& TUNCEL NB. 2016. Effect of black mulberry (Morus nigra) extract treatment on cognitive impairment and oxidative stress status of d-galactoseinduced aging mice. Pharmac Biol 54: 1052-1064. doi: 10.3109/13880209.2015.1101476.

VERGĖS B. 2015. Pathophysiology of diabetic dyslipidaemia: where are we? Diabetol 58: 886-899. doi: 10.1007/ s00125-015-3525-8.

VOLPATO GT, CALDERON IM, SINZATO S, CAMPOS KE, RUDGE MV \& DAMASCENO DC. 2011. Effect of Morus nigra aqueous extract treatment on the maternal-fetal outcome, oxidative stress status and lipid profile of streptozotocininduced diabetic rats. J Ethnopharmacol 138: 691-696. doi: 10.1016/j.jep.2011.09.044.

YUSOFF NA, AHMAD M, AL-HINDI B, WIDYAWATI T, YAM F, MAHMUD R, RAZAK KNK \& ASMAWI MZ. 2015. Aqueous Extract of Nypa fruticans Wurmb. Vinegar Alleviates Postprandial Hyperglycemia in Normoglycemic Rats. Nutrients 7: 70127026. https://doi.org/10.3390/nu7085320.

ZENI ALB, MOREIRA TD, DALMAGRO AP, CAMARGO A, BINI LA, SIMIONATTO EL \& SCHARF DR. 2017. Evaluation of phenolic compoudns and lipid-lowerring effect of Mours nigra leaves extract. An Acad Bras Cienc 89: 2805-2815. Doi: 10.1590/0001-3765201720160660.

ZHOU Q, HAN X, RONGBIN L, ZHAO W, BINGYAO B, YAN C \& DONG X. 2018. Anti-atherosclerosis of oligomeric proanthocyanidins from Rhodiola rosea on rat model via hypolipemic, antioxidant, anti-inflammatory activities together with regulation of endothelial function. Phytomed 51: 171-180. doi: 10.1016/j.phymed.2018.10.002. 


\section{How to cite}

DA SILVA DHA, BARBOSA HM, DA SILVA JF, MOURA CA, GOMES DA, ALMEIDA JRGS \& LIRA EC. 2021. Antidiabetic properties of oral treatment of hexane and chloroform fractions of Morus nigra leaves in streptozotocininduced rats. An Acad Bras Cienc 93: e20210744. DOI 10.1590/00013765202120210744.

Manuscript received on January 13, 2021;

accepted for publication on July 28, 2021

\section{DIONÍSIO H.A. DA SILVA}

https://orcid.org/0000-0002-1614-5728

HUMBERTO M. BARBOSA ${ }^{1}$

https://orcid.org/0000-0002-6447-9378

JULY F. DA SILVA

https://orcid.org/0000-0001-9589-6599

\section{CELUANE A. MOURA ${ }^{2}$}

https://orcid.org/0000-0001-5801-5975

\section{DAYANE A. GOMES ${ }^{1}$}

https://orcid.org/0000-0001-7288-1829

JACKSON R.G.S. ALMEIDA ${ }^{2}$

https://orcid.org/0000-0002-0867-1357

\section{EDUARDO C. LIRA ${ }^{2}$}

https://orcid.org/0000-0002-0388-1208
${ }^{1}$ Universidade Federal de Pernambuco, Departamento de Fisiologia e Farmacologia, Av. da Engenharia, s/n, Cidade Universitária, 50670-420 Recife, PE, Brazil

${ }^{2}$ Universidade Federal do Vale do São Francisco,

Núcleo de Estudos e Pesquisas de Plantas

Medicinais, Campus Petrolina/Centro, Av. José de Sá

Maniçoba, s/n, 56304-205 Petrolina, PE, Brazil

Correspondece to: Eduardo C. Lira

E-mail:eduardo.clira2@ufpe.br

\section{Author contributions}

D.A.G., J.R.G.S.A and E.C.L. designed the study, analyzed the data and drafted wrote the manuscript. D.H.A.S, H.M.B. and J.F.S. performed the antidiabetic and biochemical assays. C.A.M and J.R.G.S.A made the ethanolic extract of M. nigra leaves and their fraction as well as the phytochemical analysis. Each author should have collaborated sufficiently in the work to take public responsibility for appropriate portions of the content.

\section{(cc) BY}

